\title{
EFEITOS FARMACOLÓGICOS E IMUNOMODULADORES DA CLOROQUINA NA INFECÇÃO POR SARS-COV-2
}

\author{
PHARMACOLOGICAL AND IMMUNOMODULATORY EFFECTS OF \\ CHLOROCHINE ON SARS-COV-2 INFECTION
}

Vergílio Pereira Carvalho ${ }^{1 *}$, Nivia Cristina Ferreira ${ }^{2}$, Adrialdo José Santos ${ }^{3}$, Eraldo Ribeiro Ferreira Leão de Moraes ${ }^{4}$, Hugo Leonardo Shigenaga Ribeiro ${ }^{5}$, Filipe Candido Goulart ${ }^{6}$, Kênia Alves Barcelos ${ }^{7}$, Ana Paula Fontana ${ }^{8}$, Lilian Martins Lacerda ${ }^{9}$, Nayara Lôbo Coelho ${ }^{10}$, Amara Chebli Baptista ${ }^{11}$, Alissa Paodiam da Silva ${ }^{12}$, Bruno Perin Kuster ${ }^{1}$, Michele Vieira Dato Sant Anna ${ }^{1}$, Daniella Mendes de Souza Sobrinho ${ }^{1}$, Amanda Alves Sobrosa ${ }^{1}$, Jair Pereira de Melo Júnior ${ }^{13}$

${ }^{1}$ Quintanista do Internato de Medicina pela Universidade de Rio Verde, UniRV-GO.

${ }^{2}$ Médica Especialista em Infectologia pelo Hospital de Doenças Tropicais (HDT) e Universidade Federal de Goiás, UFG-GO.

${ }^{3}$ Médico Titular Especialista em Clínica Médica e Neurologia pela Universidade Federal de São Paulo, UNIFESP-SP / Escola Paulista de Medicina. Chefe no Setor de Neurooncologia da Disciplina de Neurocirurgia na UNIFESP.

4 Médico Doutor em Ciências pela UNIFESP-SP / Escola Paulista de Medicina. Titular Especialista em Cardiologia pela Sociedade Brasileira de Cardiologia (SBC), em Eletrofisiologia Clínica e Invasiva pela Sociedade Brasileira de Arritmias Cardíacas (SOBRAC) e em Marca-passo pelo Departamento de Estimulação Cardíaca Artificial (DECA) da Sociedade Brasileira de Cirurgia Cardiovascular (SBCCV). Professor adjunto no curso de Medicina na Universidade de Rio Verde, UniRV-GO.

${ }^{5}$ Médico Residente em Geriatria pela Irmandade da Santa Casa de Misericórdia de São Paulo, ISCMSP-SP e Hospital Geriátrico e de Convalescentes Dom Pedro II. Especialista em Clínica Médica pelo Centro Universitário Ingá - UNINGÁ.

6 Médico Especialista em Cardiologia pela Sociedade Brasileira de Cardiologia. Especialista em Clínica Médica pelo Hospital Municipal Prof. Dr. Alípio Corrêa Netto, HMACN-SP. Professor efetivo e Coordenador do internato de Clínica Médica na Universidade de Rio Verde, UniRV-GO.

${ }^{7}$ Doutoranda no Programa de Pós-Graduação em Ciência Animal pela Universidade Federal de Goiás - UFG. Coordenadora Pedagógica do Curso de Medicina da Universidade de Rio Verde, UniRV - GO, no Campus de Rio Verde - GO.

8 Doutoranda em Enfermagem pela Universidade Federal de Goiás - UFG. Coordenadora Pedagógica do Curso de Medicina da Universidade de Rio Verde UniRV, no Campus de Formosa - GO.

${ }^{9}$ Médica Especialista em Cirurgia Geral e em Videolaparoscopia pela Universidade Federal de Uberlândia, UFU-MG.

${ }^{10}$ Médica Especialista em Cirurgia Geral pela Santa Casa de Misericórdia de Franca/SP.

${ }^{11}$ Médica Residente em Cirurgia Geral, Santa Casa de Misericórdia de Ourinhos/SP.

12 Médica Residente em Clínica Médica, Santa Casa de Misericórdia de Ourinhos/SP.

${ }^{13}$ Doutor em Física Aplicada à Medicina e Biologia pela Universidade de São Paulo USP. Professor Titular na Universidade de Rio Verde, UniRV-GO.

* Rua 08, no 04 - Vila Renovação, Rio Verde/GO, Brasil. CEP 75906-060. E-mail: vergilio_carvalho@hotmail.com

Submetido em: 01/04/2020; Aceito em: 23/06/2020. 


\section{RESUMO}

Em dezembro de 2019, pacientes com sintomas respiratórios compareceram em algumas instituições médicas em Wuhan, na China e foram posteriormente diagnosticados com um novo tipo de pneumonia por coronavírus. A Organização Mundial da Saúde (OMS) em fevereiro de 2020 considerou a doença como uma Emergência em Saúde Pública, tratando-se de uma pandemia, conhecida como Corona Virus Disease 2019 (CoVid-19). Nesse sentido, objetiva-se com o presente artigo demonstrar registros na literatura que corroborem o uso da cloroquina no manejo clínico da CoVid-19. Trata-se de uma revisão bibliográfica, em que se utilizou as seguintes bases de dados referenciais: Biblioteca Virtual de Saúde (Bvs), Web of Science; Periódico da Capes; SciELO; PubMed e LILACS. A avaliação crítica dos artigos selecionados para redação do artigo foi realizada mediante a ferramenta Critical Appraisal Tool (CAT). Por sua vez, compreende-se que a cloroquina pode inibir a replicação de vários vírus, interagindo com a entrada viral mediada por endossoma ou com os estágios finais da replicação de vírus envolvidos. Além disso, o uso de cloroquina concomitante ao remdesivir pode ter desfechos promissores até que uma vacina possa ser desenvolvida. Portanto, a cloroquina apresenta propriedades imunomoduladoras que podem ser de interesse nas infecções virais associadas à inflamação e/ou ativação imune, necessitando de pesquisas adicionais e considerando sempre seu potencial de toxicidade ao organismo humano.

Palavras-chave: Cloroquina. Coronavírus. Infecção pelo coronavírus. Síndrome Respiratória Aguda Grave (SARS).

\section{ABSTRACT}

In December 2019, patients with respiratory symptoms attended some medical institutions in Wuhan, China, and were subsequently diagnosed with a new type of coronavirus pneumonia. In February 2020, WHO considered the disease as a Public Health Emergency, a pandemic known as Corona Virus Disease 2019 (CoVid-19). In this sense, this article aims to demonstrate findings in the literature that corroborate the use of chloroquine / hydroxychloroquine in the clinical management of CoVid-19. This is a bibliographic review, in which the following reference databases were used: Virtual Health Library (Bvs), Web of Science; Capes Journal; SciELO; PubMed and LILACS. The critical evaluation of the articles selected for writing the article was performed using the Critical Appraisal Tool (CAT). In turn, it is understood that chloroquine / hydroxychloroquine can inhibit the replication of several viruses, interacting with the viral input mediated by endossoma or with the final stages of viruses replication involved. In addition, the use of Chloroquine concomitant with remdesivir may have promising outcomes until a vaccine can be developed. Therefore, chloroquine / hydroxychloroquine has immunomodular properties that may be of interest in viral infections associated with inflammation and/or immune activation, requiring additional research, always considering its potential for toxicity to the human body. 
Keywords: Chloroquine. Coronavirus. Coronavirus infection. Severe Acute Respiratory Syndrome (SARS).

\section{INTRODUÇÃO}

Em dezembro de 2019, pacientes com sintomas respiratórios compareceram em algumas instituições médicas em Wuhan, na China e foram posteriormente diagnosticados com um novo tipo de pneumonia por coronavírus. Em 12 de janeiro de 2020, o vírus foi denominado pela Organização Mundial da Saúde (OMS) como Novel Coronavirus (2019-nCoV). A OMS em fevereiro de 2020 considerou a doença como uma Emergência em Saúde Pública, tratandose de uma pandemia, e no dia 11 do mesmo mês, a nova doença foi nomeada oficialmente como Corona Virus Disease 2019 (COVID-19) (WHO, 2020).

Compreende-se que a COVID-19 apresenta como agente etiológico um novo coronavírus, o qual é nomeado como Síndrome Respiratória Aguda Grave Coronavírus 2 (SARS-COV-2) (ZHOU et al., 2020; ZHU et al., 2020). O coronavírus é um vírus envelopado visualizado pela microscopia eletrônica, especificamente, o SARS-COV-2 se apresenta com formato esférico, possui uma fita simples de RNA em seu interior com aproximadamente $30 \mathrm{~kb}$ de comprimento sendo, portanto, um dos maiores RNAvírus conhecido, pertencente à família Coronaviridae e à ordem Nidovirales (KIM et al., 2020).

A classificação inicial do coronavírus se baseia em 3 grupos considerando fatores de ordem genética e nas associações sorológicas. O Grupo 1 possui patógenos que causam doença gastrointestinal como o Vírus da Epidemia Diarreica Porcina, Vírus da Gastroenterite Transmissível Porcina, Coronavírus Canino, Vírus da Peritonite Infecciosa Felina, Coronavírus Humano 229E (HCoV229E) e HCoV-NL63. O Grupo 2 continua com patógenos gastrointestinais e demonstra o primeiro vírus da classe com repercussões no sistema respiratório, o grupo contém o Vírus da Hepatite Murina, Coronavírus Bovino (BCoV), HCoVOC43, Vírus da Sialodacrioadenite do Rato, Vírus da Encefalomielite Hemaglutinante Porcina (PHEV), Coronavírus Respiratório Canino e o Coronavírus Equino. O SARS-COV-2, incluso neste grupo, é tido como isolado dos outros, constituindo um "subgrupo 2b" (GORBALENYA; SNIJDER; SPAAN, 2004). O Grupo 3, até o presente momento, apresenta somente vírus aviários que originam infecções brônquicas como o Coronavírus do Peru (Turkey Coronavirus) e o Vírus da Bronquite Infecciosa Aviária (VIJGEN et al., 2005).

Posto isso, os primeiros casos de SARS-COV foram relatados na China em 2002. O SARS-COV se dispersou aceleradamente para mais de doze países na América do Norte, América do Sul, Europa e Ásia, infectando mais de 8.000 mil pessoas e causando entorno de 800 mortes, antes da epidemia global de SARS-COV ser controlada em 2003. Em abril de 2012, foi identificado outro coronavírus, diferente daquele que causou a SARS-COV no início da década passada. O novo coronavírus era sem conhecimento como causador de doença humana até começar os primeiros casos de infecção, inicialmente na Arábia Saudita e, em seguida, em demais países do Oriente Médio, na Europa e na África. Todos os casos parecidos fora da Península Arábica possuíam antecedentes de viagem ou contato recente com viajantes provenientes de países do Oriente Médio - Arábia Saudita, Catar, Emirados Arabes Unidos e 
Jordânia. Nessa perspectiva, devido à área geográfica dos casos, a doença foi nomeada como Síndrome Respiratória do Oriente Médio e veiculada no mundo por meio da sigla MERS, do inglês Middle East Respiratory Syndrome, sendo o novo vírus nomeado Coronavírus associado à MERS (MERSCoV) (BRASIL, 2014).

Acredita-se que o coronavírus possui um reservatório de origem animal que, a partir de mudanças ecológicas e antrópicas como a caça, o comércio e o consumo de animais exóticos, cruzou a barreira entre espécies, species jumping, favorecendo a transmissão para humanos e em sequência a transmissão humano-humano (MENACHERY et al., 2017).

Dado o potencial de transmissibilidade e virulência do coronavírus entre os continentes, tornou-se imperativo no meio científico a busca de fármacos a fim de atenuar ou eliminar este vírus. Nesse sentido, insere-se a cloroquina que é uma 9-aminoquinolina que é conhecida desde 1934. Especificamente sintetizada para ser usada como agente antimalárico, a cloroquina se mostrou efetiva por possuir propriedades imunomoduladoras que incentivaram sua aplicação no tratamento de doenças autoimunes, como a artrite reumatoide e lúpus eritematoso sistêmico. Para estas doenças, ela representa uma contribuição farmacológica válida, uma vez que se mostrou capaz de retardar o progresso da doença e, ao mesmo tempo, mostrar toxicidade limitada (SAVARINO et al., 2003).

Por conseguinte, a tolerabilidade, o baixo custo e as propriedades imunomoduladoras da cloroquina estão associadas aos efeitos bioquímicos que sugerem seu uso, relevantemente, em infecções virais, podendo resultar em uma resposta anti-inflamatória (BOELAERT; PIETTE; SPERBER, 2001). Haja visto que se identifica na literatura que, além de inibir a produção de Fator de Necrose Turmoral a (TNF- $\alpha$ ) por macrófagos derivados de monócitos estimulados, também diminui a expressão dos receptores de superfície de TNFa nas linhagens celulares monocíticas humanas e, portanto, a sinalização de TNF- $\alpha$ mediada pelo receptor, consequentemente, prejudicando a replicação de diferentes vírus nos estágios inicial ou tardio da replicação viral (JEONG et al., 2002; SAVARINO et al., 2003).

Frente a isso, objetivou-se com este artigo demonstrar pesquisas e dados (informações) na literatura que corroborem sobre o uso da cloroquina no manejo clínico da COVID-19.

\section{METODOLOGIA}

Trata-se de uma revisão bibliográfica, em que foram elegíveis artigos primários, com data de publicação de 1995 até 2020. Para seleção dos artigos, optou-se pela busca com os operadores booleanos and (e) e or (ou), sobre coronavírus, infecção pelo coronavírus, vírus da Síndrome Respiratória Aguda Grave (SARS), Coronavírus Humano NL63, Glicoproteína da Espícula de Coronavírus, Coronavírus da Síndrome Respiratória do Oriente Médio e cloroquina.

Além disso, foram selecionados apenas artigos publicados em Língua Portuguesa, Inglesa ou Chinesa, em que se utilizou as seguintes bases de dados referenciais: Biblioteca Virtual de Saúde (Bvs), Web of Science; Periódico da 
Capes; SciELO; PubMed e LILACS. Ao finalizar as pesquisas em cada base, as referências duplicadas foram excluídas. Desse modo, 150 artigos foram selecionados para leitura e 22 incluídos na redação deste trabalho.

Considerando-se o contexto da Medicina Baseada em Evidências, surge que, a Avaliação Crítica (AC) de artigos é uma habilidade essencial para a prática baseada em evidências, cujo foco é mitigar vieses, preocupando-se em integrar as melhores evidências externas aos cuidados clínicos. Muitas revisões sistemáticas e estudos têm servido de modelos para construção de diversas diretrizes em saúde, principalmente no contexto do novo coronavírus (2019$\mathrm{nCoV}$ ) gerando diversas especulações no meio científico no que concerne 0 manejo clínico dos pacientes infectados e medidas terapêuticas.

Sendo assim, foi utilizado na seleção dos 18 artigos deste trabalho, as Ferramentas de Avaliação Crítica, do inglês, Critical Appraisal Tool (CAT). As CATs são listas de verificação ordenadas que permitem verificar a qualidade metodológica de um estudo com base em um conjunto de critérios (DOWNES et al., 2016).

\section{DESENVOLVIMENTO}

\section{Histórico da cloroquina e sua inibição na replicação viral}

A 4-aminoquinolina cloroquina é utilizada desde 1940, sendo um agente esquizonticida sanguíneo muito potente e efetivo contra as formas eritrocíticas de todas as quatro espécies de plasmódios (Plasmodium vivax, Plasmodium falciparum, Plasmodium malariae e Plasmodium ovale), entretanto, sem efeito nos esporozoítos, hipnozoítos e gametócitos (RANG et al., 2016).

No que concerne o contexto histórico que envolve a cloroquina é conhecido que sua descoberta ocorreu em 1939 pelos alemães em substituição à quinacrina. Ao final da Segunda Guerra Mundial o fármaco foi destinado ao tratamento da malária, considerando a sua segurança e efetividade em relação à quinacrina. Ainda nesta época, durante o uso do fármaco na guerra pelo exército alemão os soldados relataram melhora nos sintomas do lúpus eritematoso sistêmico (LES) e de artrite reumatoide (TANENBAUM; TUFFANELLI, 1980). Em 1989 estudos demonstraram redução na incidência do Linfoma de Burkitt em pacientes tratados profilaticamente com a cloroquina contra malária (GESER; BRUBAKER; DRAPER, 1989).

Abaixo apresenta-se a estrutura molecular da cloroquina (Figura 1), a qual é da classe terapêutica dos antimaláricos e tem como características físicas: ser um pó cristalino, branco ou quase branco, higroscópico e apresenta polimorfismo. No que tange a sua solubilidade é facilmente solúvel em água, muito pouco solúvel em etanol e metanol, praticamente insolúvel em benzeno, clorofórmio e éter etílico e suas constantes físico-químicas são: faixa de fusão (5.2.2): $193^{\circ} \mathrm{C}$ a $195^{\circ} \mathrm{C}$, para um dos polimorfos e $215^{\circ} \mathrm{C}$ a $218^{\circ} \mathrm{C}$ para o outro polimorfo (BRASIL, 2019). 
Figura 1 - Estrutura molecular da cloroquina<smiles>CCN(CC)CCCC(C)Nc1ccnc2cc(Cl)ccc12</smiles>

Fonte: Brasil (2019).

A cloroquina é uma base fraca, conhecida por acometer vesículas ácidas, causando à alteração de diversas enzimas. No meio extracelular, a cloroquina está existente essencialmente em uma conformação protonada que, devido à sua carga positiva, é incapaz de atravessar a membrana plasmática. Porém, a porção não protonada pode entrar no meio intracelular, em que, por sua vez, fica protonada de modo inversamente proporcional ao $\mathrm{pH}$, em conformidade com a lei de Henderson-Hasselbach. Logo, por este mecanismo é compreendido que a cloroquina se concentra em organelas ácidas, como o endossoma, as vesículas de Golgi e os lisossomos, locais que apresentam pH baixo e a maioria das moléculas do fármaco são carregadas positivamente (CANADIAN RHEUMATOLOGY ASSOCIATION, 2000). O fármaco é liberado para o meio extracelular principalmente por exocitose ou pela ação da proteína de resistência a múltiplos farmácos MRP-1, um transportador de fármacos na superfície celular pertencente à família de cassetes de ligação ao ATP (VEZMAR; GEORGES, 1998).

Outrossim, é determinado que bases fracas, ao aumentarem o $\mathrm{pH}$ das vesículas lisossômicas e da rede trans-Golgi (TGN), suprimem inúmeras ações de enzimas, incluindo hidrolases ácidas, e inibem a modificação pós-traducional de proteínas recém-sintetizadas. $\mathrm{O}$ incremento mediado pela cloroquina no $\mathrm{pH}$ endossômico altera o metabolismo do ferro nas células humanas prejudicando a liberação endossômica de ferro da transferrina, diminuindo, assim, a concentração intracelular de ferro. Essa diminuição, prejudica a função de várias enzimas celulares envolvidas em vias que levam à replicação do DNA celular e à expressão de diferentes genes (LEGSSYER et al., 2003).

Diante do exposto, percebe-se que a cloroquina pode afetar a replicação de vários vírus, interagindo com a entrada viral mediada por endossoma ou com os estágios finais da replicação de vírus envolvidos (Figura 2) (SAVARINO et al., 2003).

Alguns vírus adentram nas células por endocitose, consequentemente, esse processo justifica a presença do vírus no lisossomo, região de $\mathrm{pH}$ baixo, que juntamente com a ação das enzimas, inibe a partícula viral, liberando o ácido nucleico infeccioso e, em vários casos, as enzimas necessárias para a replicação viral. Análogo a isso, foi demonstrado que a cloroquina inibe diferentes vírus que requerem uma etapa dependente do $\mathrm{pH}$ no lisossomo, como o vírus da doença de Borna (GONZALEZ-DUNIA; CUBITT; DE LA TORRE, 1998), o Minute Virus of Mice (MVM) (ROS; BURCKHARDT; KEMPF, 2002) e o vírus da leucose do sarcoma aviário (DIAZ-GRIFFERO, 2000). De particular interesse para a 
patologia humana é o estudo de que a cloroquina inibe o desnudamento do vírus da hepatite A, impedindo todo o seu ciclo de replicação (BISHOP, 1998).

Figura 2 - Etapas da replicação de diferentes vírus na célula. A cloroquina pode impedir a replicação dos vírus nos estágios iniciais ou tardios.

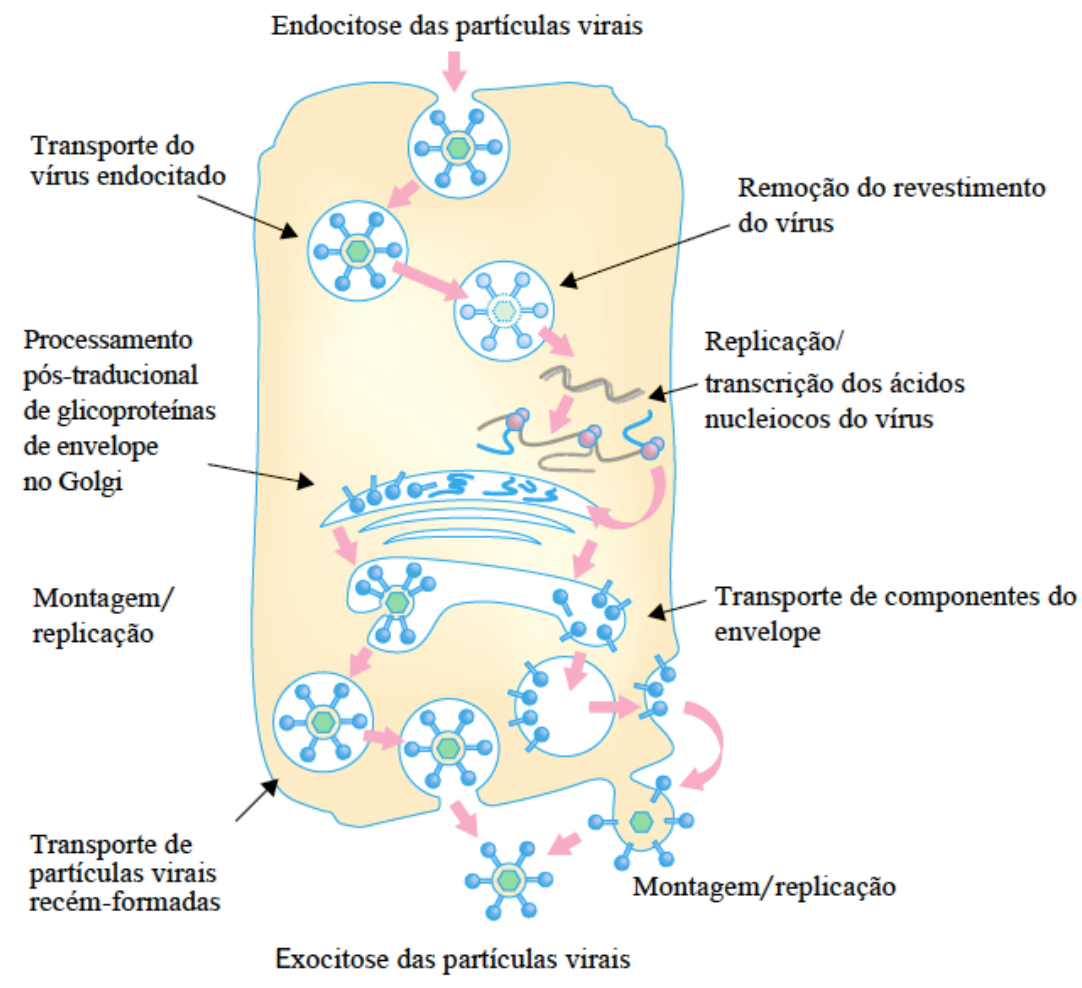

Fonte: Savarino et al. (2003), adaptado.

\section{Efeitos da cloroquina no sistema imune}

O acúmulo de cloroquina em linfócitos e macrófagos resulta em propriedades anti-inflamatórias e levou ao seu uso clínico em condições como artrite reumatoide, lúpus eritematoso sistêmico (LES) e sarcoidose, sendo a última caracterizada por uma superprodução do fator de necrose tumoral alfa (TNF- $\alpha$ ) pelos macrófagos alveolares (BAUGHMAN; LOWER; DU BOIS, 2003).

Além de inibir a produção de TNF-a por macrófagos derivados monócitos estimulados, a cloroquina também diminui a expressão da superfície dos receptores de TNF- $\alpha$ nas linhagens celulares monocíticas humanas e, portanto, a sinalização de TNF-a mediada pelo receptor (JEONG et al., 2002). Os resultados de tal comprometimento da sinalização mediada por TNF- $\alpha$ são mostrados na Figura 3.

Ademais, estes fármacos também afetam a apresentação antigênica na pele, pelos queratinócitos e células de Langerhans, além de estabilizar a membrana lisossomal. À vista disso, com a ausente interação entre as células apresentadoras de antígenos e os linfócitos $\mathrm{T}$ CD4+, há uma redução na liberação de interleucina 1 (IL-1), interleucina 6 (IL-6) e TNFa e isto possibilita um efeito anti-inflamatório. A cloroquina, também interfere nas reações antígenoanticorpo dependentes do complemento e inibe a produção de superóxidos por leucócitos ativados (RANG et al., 2016). 
Figura 3 - Efeitos da cloroquina no sistema imune.

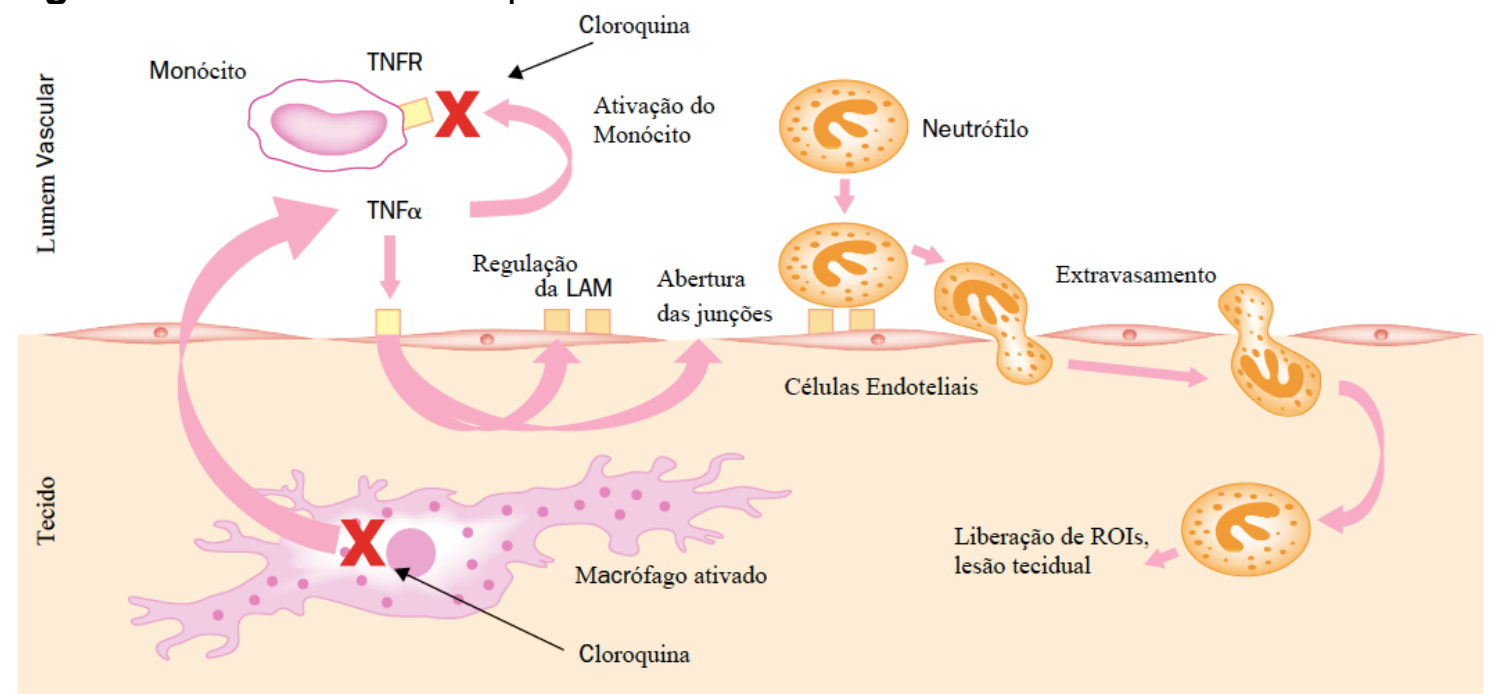

Notas: O TNF-a é produzido por monócitos/macrófagos ativados. Entre suas múltiplas funções, ajuda a ativar monócitos em repouso e favorece o extravasamento de neutrófilos, abrindo junções estreitas entre células endoteliais vasculares humanas e regulando positivamente as moléculas de adesão a leucócito (LAM). A cloroquina diminui a produção de TNF e regula negativamente os receptores 1 e 2 do TNFa (TNFR) na superfície celular dos monócitos, o que acaba resultando em diminuição da ativação dos monócitos e extravasamento de leucócitos. Cruzes vermelhas marcam os passos diretamente inibidos pela cloroquina.

Fonte: Savarino et al. (2003)

\section{Segurança na administração da cloroquina}

O uso da cloroquina por meio século na terapia da malária demonstra a segurança da administração aguda em seres humanos. O seu uso em doenças reumáticas e na profilaxia antimalárica mostrou baixa incidência de eventos adversos durante a administração crônica deste fármaco por períodos de até alguns anos (HERMAN; LEYS; SPILEERS, 2002). Um estudo forneceu resultados encorajadores sobre a segurança de uma dose alta da cloroquina (até $500 \mathrm{mg}$ de base de cloroquina por dia), mesmo durante a gravidez (KLINGER et al., 2001).

Vale destacar que a cloroquina tem poucos efeitos adversos, quando administrada para quimioprofilaxia. Quando há o uso de doses maiores em crises agudas da malária, os sintomas se intensificam e podem levar até um quadro de retinopatia e perda da audição. Além disso, as injeções em bolus intravenoso podem causar hipotensão e arritmias. Alterações neurológicas também são documentadas e caracterizadas por insônia, nervosismo, irritabilidade e cefaleia, porém deixam de estarem presentes após as primeiras semanas de uso, podendo, de forma menos frequente, apresentar convulsões tônico-clônicas, transtorno depressivo e psicose (RANG et al., 2016).

As manifestações dermatológicas são o prurido, alterações pigmentares da pele e mucosas, fotossensibilidade, pênfigo bolhoso, eritema pigmentar fixo, eritema anular, eritrodermia, erupção liquenoide e exacerbação da psoríase (LACAVA, 2010). 


\section{Progressão na mutação do coronavírus com novas cepas}

A partir de 2002 até novembro de 2019 mais 3 cepas do coronavírus haviam sido descobertas, levando o vírus a deixar de ser visto como inofensivo. Em 2002 um novo Coronavírus Humano (HCoV) apresentando apenas pouca similaridade antigênica e genética com as cepas anteriores foi identificado como possível causador de Síndrome Respiratória Aguda Grave (SARS), uma severa desordem pulmonar, podendo ser seguida de infecção sistêmica e eventualmente morte em $10 \%$ dos casos, ficando conhecido como SARS-COV (KEYAERTS et al., 2009).

Nos 3 anos subsequentes, dois outros tipos de Coronavírus foram reconhecidos como causadores de doença respiratória em humanos, o HCoVNL63 associado à características genéticas e sorológicas do Grupo 1, causador de disfunção respiratória aguda, além de ser um dos patógenos reconhecidos como causa de CRUPE em crianças, e o HCoV-HKU1 também associado à bronquiolite e pneumonia, identificado pela primeira vez em janeiro de 2005, em um homem de 71 anos hospitalizado que havia retornado recentemente a Hong Kong de Shenzhen, na China. Demonstrava desconforto respiratório agudo e pneumonia bilateral confirmada com radiografias (CHIU et al., 2005; LAU et al., 2006).

Apesar de falhas sucessivas nas tentativas de cultivar uma linha celular a partir do HCoV-HKU1, estudos foram capazes de obter a sequência genômica completa. A análise filogenética mostrou que o HCoV-HKU1 está mais intimamente relacionado ao Vírus da Hepatite Murina, colocando-o no Grupo 2 apesar de sua distinção em outros aspectos com outros betacoronavírus humanos conhecidos deste mesmo grupo, como o HCoV-OC43 (LAU et al., 2006).

\section{A inibição do SARS-COV-2 com uso da cloroquina e a associação de outras abordagens terapêuticas}

Como exposto, o coronavírus teve o seu status de vírus indolente até o terceiro tipo, sendo estes mais prevalentes em animais, principalmente ratos, porcinos, equinos, caninos e felinos. Essa concepção mudou totalmente com a emergência do SARS-COV que rapidamente se alastrou, rompendo barreiras intercontinentais e alcançando índices de mortalidade de aproximadamente $10 \%$. Porém, por sua autorresolução, em poucos meses, gerou-se uma corrida inicial pela busca de um tratamento efetivo, todavia sem nenhum estudo em humanos, embora houve pesquisas em espécies não humanas. Com isso, demonstrou-se, a concentração de alguns fármacos com índices de dose efetiva em níveis tão baixos como da ordem de microdose para concentração terapêutica em leite de ratos no tratamento de filhotes, no entanto a grande maioria dos estudos não passaram da fase de estudo in vitro, utilizando linhagem genética celular VERO, VERO-E6, Huh (WANG et al., 2020).

O mesmo se repetiu durante os novos surtos de coronavírus com o quinto tipo que não ultrapassou os limites do continente asiático e o sexto tipo, o qual ficou denominado de Síndrome Respiratória do Oriente Médio (MERS) e chegou a alcançar regiões do Mediterrâneo e atingir índices alarmantes de $30 \%$ de mortalidade, porém, sendo ambos autolimitados. $O$ interesse nas pesquisas 
acompanhou essa tendência e, limitou-se ao término de estudos já iniciados (ZUMLA et al., 2016).

Atualmente, uma nova fase de estudos vêm sendo direcionados com os objetivos de conhecer o novo coronavírus, denominado de Síndrome Respiratória Aguda Grave Coronavírus 2 (SARS-COV-2) e buscar uma forma de determinar um tratamento efetivo que possa dar tempo para o sistema imune mitigar a infecção ou que vise diretamente a cura, além de estudos in vitro que compararam a eficácia de diversos fármacos em uso pré e pós infecção, avaliando principalmente dados sobre os estudos feitos nos tipos anteriores do vírus e a capacidade dos fármacos atuarem nos diferentes $\mathrm{HCoV}$, do mesmo modo em outros vírus como Influenza, Vírus da Imunodeficiência Humana (HIV), Vírus da Hepatite, entre outros. Mas, infelizmente ainda sem nenhum estudo definitivo demonstrando eficácia específica antiCOVID-19 (WANG et al., 2020).

Com base em informações semelhantes, a cloroquina passou a ser um avaliada como opção para o tratamento anticoronavírus por mostrar eficácia in vitro contra um largo espectro viral atuando no fagossomo com aumento do $\mathrm{pH}$ dentro da organela alterando a acidez necessária para a replicação, fusão viral e para a exocitose, por intermédio da quelação de íons $\mathrm{H}^{+}$com as porções nitrogenadas da molécula do fármaco, além do efeito anti-inflamatório que propicia melhora no quadro de pneumonia nos casos mais graves e, isso se dá através da supressão da produção e liberação de TNF-a e IL-6 (KEYAERTS et al., 2004).

Na época do SARS-COV, vários fármacos foram testados com base em sua efetividade antiviral, entre elas, a Teicoplanina um antibiótico glicopeptídeo e a cloroquina repetindo os dados de outros estudos em relação à Concentração Efetiva 50\% (EC50) de aproximadamente $8 \mu \mathrm{M}$ quando adicionado a meios de cultura antes e após exposição viral, além de diversas outros fármacos. A partir disso, há evidências da eficácia in vitro contra o SARS-COV-2 com o uso do remdesivir, um fármaco antinfluenza, análogo de nucleosídeo com boa ação contra RNAvírus e a cloroquina, a qual atua na redução da replicação viral. Vale salientar o baixo custo de produção deste segundo fármaco e a impossibilidade de haver dentre outros fármacos já pesquisados, a qual possui mais baixo nível de efeitos adversos na dose necessária para o efeito esperado (COLSON; ROLAIN; RAOULT, 2020), considerando apenas alguns estudos, pois não é de consenso geral e há muitas controvérsias sobre uma dose segura com uso da cloroquina.

Além disso, é identificado o início dos avanços nos estudos mais voltados para o SARS-COV-2, em que também foi sugerido cerca de 30 agentes com possível ação antiviral compatível com as características do SARS-COV-2 dos quais foram constatados bom perfil de ação para os fármacos cloroquina via oral (VO) (VO 300mg 12/12h), fosfato de cloroquina (VO 500mg 12/12h), remdesivir, arbidol (VO 200mg 8/8h) e flavipiravir o que deu base para o 6ㅇ Guidelines for the Prevention, Diagnosis, and Treatment of Novel Coronavirus-induced Pneumonia proposto pela National Health Commission (NHC) da China em 18 de Fevereiro de 2020 (Quadro 1) (DONG; HU; GAO, 2020). 
Quadro 1 - Antivirais incluídos na 6o versão no Guideline de tratamento do SARS-COV-2

\begin{tabular}{|c|c|c|c|}
\hline Fármaco & $\begin{array}{c}\text { Via de } \\
\text { administração }\end{array}$ & Posologia & Duração do tratamento \\
\hline IFN- $\alpha$ & Inalatória & $\begin{array}{l}5 \text { milhões de } U \text { ou } \\
\text { equivalente } \\
\text { administração } 02 \\
\text { ao dia }\end{array}$ & Não mais que 10 dias \\
\hline $\begin{array}{l}\text { Lopinavir / } \\
\text { ritonavir }\end{array}$ & Oral & $\begin{array}{l}200 \text { mg / } 50 \text { mg / cápsula, } \\
\text { até } 02 \text { vezes ao dia }\end{array}$ & Não mais que 10 dias \\
\hline Ribavirina & Endovenoso & $\begin{array}{l}500 \text { mg / } 02 \text { a } 03 \text { vezes ao } \\
\text { dia em combinação com } \\
\text { IFN- } \alpha \\
\text { Lopinavir/ritonavir }\end{array}$ & Não mais que 10 dias \\
\hline Cloroquina & Oral & $500 \mathrm{mg}, 02$ vezes ao dia & Não mais que 10 dias \\
\hline Arbidol & Oral & $200 \mathrm{mg}, 03$ vezes ao dia & Não mais que 10 dias \\
\hline
\end{tabular}

Fonte: Dong et al. (2020), adaptado.

No $5^{\circ}$ Guideline já haviam sido incluído recomendações acerca do uso de IFN- $\alpha$ inalatório (INL) (INL dose 5 milhões $U$ diluída em $2 \mathrm{ml}$ de água destilada 12/12h), lopinavir/ritonavir (VO 400/100mg 12/12h) e ribavarina (EV 500mg $12 / 12 \mathrm{~h}$ combinado com IFN- $\alpha$ ) para o tratamento da pneumonia induzida pelo SARS-COV-2. Todos com tratamento por período de até 10 dias. Ainda foi reforçado o dado de que a cloroquina consegue impedir ou bloquear a infecção por SARS-COV-2 em doses micromoleculares (DONG; HU; GAO, 2020).

Existem ainda evidências correlacionadas ao tratamento da MERS, vírus que surgiu em 2012 na região do mediterrâneo, na Arábia Saudita, e alcançou alarmantes índices de $30 \%$ de mortalidade. Uma revisão sistemática com 348 fármacos aprovados pelo Food and Drug Administration (FDA) dentre os quais quatro compostos foram selecionados por apresentar melhor atividade antiMERS in vitro, a cloroquina estava entre estes, reforçando sua atuação antiSARS-COV e antiHCoV229E (DE WILDE et al., 2014).

Quanto ao mecanismo de entrada do patógeno SARS-CoV-2 no organismo humano, evidências da Sociedade Europeia de Cardiologia apontam a associação do vírus com a enzima conversora de angiotensina 2 (ECA2). Essa enzima funciona como um receptor viral e está amplamente distribuída nos tecidos, incluindo células epiteliais alveolares pulmonares, endotélio vascular, coração, rim e testículo (SAMA et al., 2020).

Os estudos sinalizam que o vírus tem o poder de gerar uma suprarregulação da Enzima Conversora de Angiotensina 2 (ECA2) (WANG; CHENG, 2020), enzima esta, que o vírus se liga para facilitar a sua entrada definitiva nas células infectadas e é nesse contexto que a $C Q$ poderia gerar uma glicosilação da ECA2 e, portanto, prevenindo o processo de ligação inicialmente descrito como uma nova forma de interação medicamentosa com o vírus, inibindo a sua liberação intracelular consecutiva (DEVAUX et al., 2020; ZHOU et al., 2020).

Ainda é demonstrada a relevância do uso de imunomoduladores como corticosteroides, no caso de pneumonia grave e associação com IFN-2a, Ciclosporina, imbuindo esse efeito também na cloroquina permitindo a 
capacidade de redução da replicação da MERS dose dependente com EC50 de 3.0 $\mathrm{MM}$, reforçando o efeito de amplo espectro desse fármaco apesar de constatar que para a MERS o uso de cloroquina, 1 hora pós infecção, não apresentou bons resultados, recomendando o uso pré-exposição. Para tanto, é preciso maiores pesquisas com a combinação de cloroquina com lopinavir por também apresentar boa EC50 em microdosagem e bom efeito pré e pós infecção (WONG; YUEN, 2008).

\section{Principais evidências em fisiopatologia sobre a cloroquina no combate ao SARS-COV-2}

A cloroquina se mostrou um fármaco de baixo custo, bom perfil EC50 e repetidas vezes citada por exibir bom padrão de inibição da replicação, fusão e a própria inibição causada pelo Coronavírus na imunidade do hospedeiro, através de vias de aumento do $\mathrm{pH}$ intraendossomal e inibição de citocinas proinflamatórias (TNF- $\alpha$ e IL-6) respectivamente.

Entende-se que a afecção causada pelo HCoV-229E em células pulmonares de linhagem fetal humana e o uso específico da cloroquina, apontando além dos efeitos supracitados, o potencial de inibição da via da p38 Proteina Kinase Ativada por Mitógeno (MAPK) e o efeito sobre a Kinase Regulada por Sinal Extracelular (ERK), com bons resultados em relação à inibição da p38 e resultados que demonstram aumento de via ERK (XIA et al., 1995).

No contexto atual, a fim de estabelecer um direcionamento do uso da cloroquina mais específico para o SARS-COV-2 e encontram-se novas pesquisas do seu uso em associação com um novo fármaco análogo de nucleosídeo com boa atividade antiRNAvírus denominado remdesivir. Estudo realizado por Wang et al. (2020), avaliou sete fármacos: ribavarina, penciclovir, nitazoxanida, nafamostat, cloroquina, remdesivir e favipiravir, todas com amplo espectro antiviral. Destas, três análogos de nucleosídeos tiveram melhores resultados em relação a inibir a replicação viral: a ribavarina, penciclovir e favipiravir, sendo que, o remdesivir e a cloroquina alcançaram dose efetiva, em baixa concentração (WANG et al., 2020).

Dessa forma, o uso da cloroquina concomitante ao remdesivir pode ter desfechos promissores até que uma vacina possa ser desenvolvida, visto que a melhor forma de combate à infecções virais se dá por bloqueio da entrada do vírus na célula ou vias que possibilitem a morte do vírus por estimulo de anticorpos criados por linfócitos B ou por estimulo direto de celular CD-8 conhecidas como natural killers (NK). Os fármacos que impedem a replicação de microrganismos encontram nos vírus a maior possibilidade de indução de mutações que por vezes são deletérias para o vírus, mas que podem propiciar uma mutação "positiva" gerando uma nova cepa mais resistente.

\section{CONSIDERAÇÕES FINAIS}

Os estudos revisados aqui mostram que a cloroquina tem efeitos antivirais in vitro e propriedades anti-inflamatórias que podem ser de interesse nas infecções virais associadas à inflamação e/ou ativação imune. Para tanto, antes de analisar os efeitos potenciais de um fármaco em uma doença, é necessário 
atender aos critérios de segurança para estimar a relação risco/benefício. Compreende-se em estudos atuais a potente inibição da infecção in vitro do SARS-COV-2, sendo, também, relevantes novos estudos com o uso de cloroquina em associação com remdesivir.

\section{REFERÊNCIAS}

BAUGHMAN, R. P.; LOWER, E. E.; DU BOIS, R. M. Sarcoidosis. The Lancet, v. 361, p. 1111- 1118, 2003.

BISHOP, N. E. Examination of potential inhibitors of hepatitis A virus uncoating. Intervirology, v. 41, p. 261-71, 1998.

BOELAERT, J. R.; PIETTE, J.; SPERBER, K. The potential place of chloroquine in the treatment of HIV-1-infected patients. Journal of Clinical Virology, v. 20, p. 137-140, 2001.

BRASIL. Agência Nacional de Vigilância Sanitária. Farmacopeia Brasileira, 7ạ. ed. São Paulo: Atheneu, 2019.

BRASIL. Secretaria de Vigilância em Saúde. Informe Técnico - MERS-CoV (Novo Coronavírus). Brasília: Ministério da Saúde, 2014.

CANADIAN RHEUMATOLOGY ASSOCIATION. Canadian Consensus Conference on hydroxychloroquine. Journal of Rheumatolgy, v.27, p. 29192921, 2000.

CHIU, S. S. et al. Human Coronavirus Infection NL63 and Other Coronavirus Infections in Hospitalized Children with Acute Respiratory Diseases in Hong Kong, China. Clinical Infectious Diseases, v. 40, p. 1721-1729, 2005.

COLSON, P.; ROLAIN, J. M.; RAOULT, D. Chloroquine for the 2019 novel coronavirus. International Journal of Antimicrobial Agents, v. 55, n. 3, p. 105923, 2020.

DEVAUX, C. A. et al. New insights on the antiviral effects of chloroquine against coronavirus: what to expect for COVID-19? International Journal of Antimicrobial Agents, v. 55, n. 5, p. 1-6, 2020.

DE WILDE, A. H. et al. Screening of an FDA-approved compound library identifies four small-molecule inhibitors of Middle East respiratory syndrome coronavirus replication in cell culture. Antimicrobial Agents and Chemotherapy, v. 58, n. 8, p. 4875-4884, 2014.

DONG, L.; HU, S.; GAO, J. Discovering drugs to treat coronavirus disease 2019 (COVID-19). Drug Discoveries Therapeutics, v. 14, n. 1, p. 58-60, 2020. 
DOWNES, M. J. et al. Development of a critical appraisal tool to assess the quality of cross-sectional studies (AXIS). Biomedical Research e Developments Open, v. 6, n. 12, p. 01-07, 2016.

GESER, A.; BRUBAKER, G.; DRAPER, C. C. Effect of a malaria suppression program on the incidence of African Burkitt's lymphoma. American Journal of Epidemiology, v. 129, p. 740-752, 1989.

GONZALEZ-DUNIA, D.; CUBITT, B.; DE LA TORRE, J. C. Mechanism of Borna disease virus entry into cells. Journal of Virology, v. 72, p. 783-788, 1998.

GORBALENYA, A. E.; SNIJDER, E. J.; SPAAN, W. J. Severe acute respiratory syndrome coronavirus phylogeny: toward consensus. Journal of Virology, v. 78, p. 7863-7866, 2004.

HERMAN, K.; LEYS, A.; SPILEERS, W. (Hydroxy)- chloroquine retinal toxicity: two case reports and safety guidelines. Bulletin of the Societe belge d'ophtalmologie, v. 284, p. 21-29, 2002.

JEONG, J. Y. et al. Chloroquine decreases cell-surface expression of tumour necrosis factor receptors in human histiocytic U-937 cells. The Journal of Immunology, v. 105, p. 83-89, 2002.

KEYAERTS, E. et al. Antiviral Activity of Chloroquine against Human Coronavirus OC43 Infection in Newborn Mice. Antimicrobial Agents and Chemotherapy, v. 53, n. 8, p. 3416-3421, 2009.

KEYAERTS, E. et al. In vitro inhibition of severe acute respiratory syndrome coronavirus by chloroquine. Biochemical and Biophysical Research Communications, v. 323, n. 1, p. 264-268, 2004.

KIM, J. M. et al. Identification of Coronavirus Isolated from a Patient in Korea with COVID-19. Osong Public Health Research Perspectives, v. 11, p. 3-7, 2020.

KLINGER, G. et al. Ocular toxicity and antenatal exposure to chloroquine or hydroxychloroquine for rheumatic diseases. The Lancet, v. 358, n. 9284, p. 813814, 2001.

LACAVA, A. C. Complicações oculares da terapêutica com a cloroquina e derivados. Arquivos Brasileiros de Oftalmologia, v. 73, n. 4, p. 384-389, 2010.

LAU, S. K. P. et al. Coronavirus HKU1 and other coronavirus infections in Hong Kong. Journal of Clinical Microbiology, v. 44, p. 2063-2071, 2006.

LEGSSYER, R. et al. Changes in function of iron-loaded alveolar macrophages after in vivo administration of desferrioxamine and/or chloroquine. Journal Inorganic Biochemistry, v. 94, p. 36-42, 2003. 
RANG, H. P. et al. Rang \& Dale Farmacologia. 8ª edição São Paulo: Elsevier, 2016, p. 655-666.

ROS, C.; BURCKHARDT, C. J.; KEMPF, C. Cytoplasmic trafficking of minute virus of mice: low-pH requirement, routing to late endosomes, and proteasome interaction. Journal of Virology, v. 76, p. 12634-12645, 2002.

MENACHERY, V. D. et al. Jumping species-a mechanism for coronavirus persistence and survival. Current Opinion in Virology, v. 23, p. 1-7, 2017.

SAMA, I. E. et al. Circulating plasma concentrations of angiotensin-converting enzyme 2 in men and women with heart failure and effects of renin-angiotensinaldosterone inhibitors. European Heart Journal, v. 41, ed. 19, p. 1810-17, 2020.

SAVARINO, A. et al. Effects of chloroquine on viral infections: an old drug against today's diseases. The Lancet Infectious Diseases, v.3, n.11, p. 722-727, 2003.

TANENBAUM, L; TUFFANELLI, D. L. Antimalarial agents. Chloroquine, hydroxychloroquine, and quinacrine. Archives of Dermatology, v. 116, p. 58791, 1980.

VEZMAR, M.; GEORGES, E. Direct binding of chloroquine to the multidrug resistance protein (MRP): possible role for MRP in chloroquine drug transport and resistance in tumor cells. Biochemical Pharmacology, v. 56, p. 733-742, 1998.

VIJGEN, L. E. et al. Complete genomic sequence of human coronavirus OC43: molecular clock analysis suggests a relatively recent zoonotic coronavirus transmission event. Journal of Virology, v. 79, p. 1595-1604, 2005.

WANG, M. et al. Remdesivir and chloroquine effectively inhibit the recently emerged novel coronavirus (2019-nCoV) in vitro. Cell Research, v. 30, p. 269271, 2020.

WHO. Pneumonia of unknown cause in China, 2020. Disponível em: https://www.who.int/csr/don/05-january-2020-pneumonia-of-unkown-causechina/en/. Acesso em: 27.mar. 2020.

WONG, S. S.; YUEN, K. Y. The management of coronavirus infections with particular reference to SARS. Antimicrobial Agents and Chemotherapy, v. 62, p. 437-441, 2008.

XIA, Z. et al. Opposing effects of ERK and JNK-p38 MAP kinases onapoptosis. Science, v. 24, p. 1326-1331, 1995.

ZHOU, P. et al. A pneumonia outbreak associated with a new coronavirus of probable bat origin. Nature, v. 579, p. 270-273, 2020. 
ZHU, N. et al. A Novel Coronavirus from Patients with Pneumonia in China, 2019. New England Journal of Medicine, v. 382, p.727-733, 2020.

ZUMLA, U. et al. Coronavirus - drug discovery and therapeutic options. Nature Reviews Drug Discovery, v. 15, p. 327-347, 2016. 